\title{
Memantine and Q-VD-OPh Treatments in Experimental Spinal Cord Injury: Combined Inhibition of Necrosis and Apoptosis
}

\author{
Aydin AYDOSELI' ${ }^{1}$, Halil CAN ${ }^{2}$, Yavuz ARAS ${ }^{1}$, Pulat Akin SABANCI ${ }^{1}$, Mehmet Osman AKCAKAYA ${ }^{3}$, \\ Omer Faruk UNAL ${ }^{1}$
}

${ }^{1}$ Istanbul University, Istanbul School of Medicine, Department of Neurosurgery, Istanbul, Turkey

${ }^{2}$ Medicine Hospital Asia, Department of Neurosurgery, Istanbul, Turkey

${ }^{3}$ Taksim Training and Research Hospital, Department of Neurosurgery, Istanbul, Turkey

\section{ABSTRACT}

AIM: To evaluate the effects of NMDA receptor antagonist memantine and pancaspase inhibitor Q-VD-Oph in combination or alone in experimental spinal cord injury.

MATERIAL and METHODS: 45 male Sprague-Dawley rats were divided into five groups. Spinal cord injury was created with the clip compression technique. The drugs were administered either alone of in combination to the subjects according to their groups. Motor function was assessed with Tarlov's motor grading scale and the inclined plane technique. The subjects were sacrificed at the fifth postoperative day. Histopathological examination was done with the use of hematoxylin eosin and TUNEL staining.

RESULTS: The results for TUNEL staining and apoptotic cell counts revealed statistically significant differences in Q-VD-Oph and combined treatment groups. Tarlov motor grading scale and inclined plane test results were also found significantly better in these two groups.

CONCLUSION: Combined use of memantine and Q-VD-OPh provides better histological and clinical results. The combined inhibition of the two major pathways, necrosis and apoptosis, needs to be further assessed with in-vivo or in-vitro studies.

KEYWORDS: Spinal cord injury, Q-VD-OPh, Apoptosis, Memantine, Necrosis, Neuroprotection

\section{INTRODUCTION}

$\mathrm{S}$ pinal cord injury (SCl) consists of two stages of tissue damage: primary traumatic damage and secondary damage. Primary traumatic damage is irreversible. Therefore experimental studies mainly focus on the prevention of the secondary damage in SCl. Secondary damage is caused by two major cell death mechanisms: Necrosis and apoptosis $(3,4,14-16,18-24)$. Apoptosis is a "programmed cell death" with cell autodigestion through enzymatic reactions and cell removal by phagocytes, without an inflammatory reaction. The importance of apoptotic cell death following $\mathrm{SCl}$ has been clearly understood in the last two decades $(19,21,23)$.
Caspases are the key regulator of apoptosis $(18,23,28)$. Several experimental studies investigated the protective effects of various caspases on secondary damage following $\mathrm{SCl}$ via inhibition of apoptotic cell death and promising results have been obtained $(3,4,21,38,39)$. Q-VD-OPh is a wide-spectrum irreversible inhibitor of pancaspases (2). Compared to other caspases, it has reduced cellular toxicity and increased potency (4). Recent researches showed that Q-VD-OPh is an effective antiapoptotic agent, which provided neuroprotection in experimental cerebral ischemia-hypoxia and stroke models (33). In an experimental model of SCl by Colak et al., apoptotic cell counts were reduced and neurological function scores were significantly better with the use of Q-VD-OPh (4). 
Excitotoxicity has been postulated as the most important factor of necrosis causing posttraumatic neuronal degeneration $(6,7)$. Glutamate is the crucial excitatory neurotransmitter in the central nervous system. In case of a decrease in cellular energy levels due to ischemia or hypoxia, glutamate causes neurotoxicity through the $\mathrm{N}$-methyl-D-aspartate (NMDA) receptor activation and intracellular calcium ion influx (2). NMDA receptor antagonists were well studied in the prevention of secondary damage following SCI $(14,15)$. Memantine (1-amino-3,5-dimethyladamantane) is a non-competitive NMDA receptor antagonist. Memantine is known for its neuroprotective effects against glutamate and NMDA induced excitotoxicity $(11,36)$. Ehrlich et al. demonstrated the neuroprotective effects of memantine in an experimental spinal cord ischemia-reperfusion model (8).

Although several studies investigated the effects of caspase inhibition or NMDA receptor inhibition for the prevention of secondary damage after $\mathrm{SCl}$ separately, to our knowledge no study has focused on the effects of combined inhibition of apoptotic and necrotic pathways, except one other study (37). In our study, we investigated the effects of individual and combined use of NMDA receptor antagonist memantine and pancaspase inhibitor Q-VD-OPh to minimize secondary damage after SCl by blocking two major mechanisms of cell loss, namely apoptosis and necrosis.

\section{MATERIAL and METHODS}

A total of 45 male Sprague-Dawley rats weighing 250-300 g obtained from the Research Center for Experimental Medicine were used for the study. The animals were fed a normal diet and housed under diurnal light conditions during the study period. All experimental protocols were approved by the local institutional animal care and use committee and institutional ethical committees of Istanbul University. The current research was conducted according to the Declaration of Helsinki and relevant laws and regulations.

\section{Experimental Groups}

The rats were allocated randomly into the five groups. Each group consisted of 9 animals $(n=9)$. The animals were followed-up for the next five days after the procedure.

Group 1 (Trauma group): Following the laminectomies only the $\mathrm{SCl}$ was produced.

Group 2 (Placebo group): Following the laminectomies and $\mathrm{SCl}$, physiological serum $(0.9 \% \mathrm{NaCl})$ was intraperitoneally administered immediately and for the following five days daily.

Group 3 (Q-VD-OPh group): Following the laminectomies and $\mathrm{SCl}, 0.4 \mathrm{mg} / \mathrm{kg}$ of $\mathrm{Q}-\mathrm{VD}-\mathrm{OPh}$ was intraperitoneally administered immediately and for the following five days daily.

Group 4 (Memantine group): Following the laminectomies and $\mathrm{SCl}, 20 \mathrm{mg} / \mathrm{kg}$ of memantine was intraperitoneally administered immediately and for the following five days daily.

Group 5 (Combined treatment group): Following the laminectomies and SCl, $20 \mathrm{mg} / \mathrm{kg}$ of memantine and $0.4 \mathrm{mg} / \mathrm{kg}$ of QVD-OPh was intraperitoneally administered immediately and for the following five days daily.

\section{Traumatic Injury Model}

The $\mathrm{SCl}$ was produced by acute spinal cord compression technique as described by Rivlin and Tator (35). Yaşargil FE 716K (Aesculap/Germany, closing force $110 \mathrm{~g}$ ) aneurysm clips were used for the spinal cord compression of 30 seconds.

\section{Surgical Procedure}

Surgical procedures were performed under general anesthesia with spontaneous breathing. General anesthesia was achieved with intraperitoneal injection of $9 \mathrm{mg} / \mathrm{kg}$ xylazine (Rompun-Bayer, Istanbul, Turkey) and $60 \mathrm{mg} / \mathrm{kg}$ ketamine (Ketalar-Eczacıbası, Istanbul, Turkey). The rats were placed in the prone position. The dorsal region of each rat was shaved and scrubbed with povidone iodine solution (Adeka, Samsun, Turkey). A midline incision was carried out and paravertebral muscles were bluntly dissected. A midthoracal two-level (approximately T7-T9) laminectomies and bilateral facetectomies were performed in order to expose the spinal cord widely. The dura was left intact. $\mathrm{SCl}$ was produced by clip compression method of Rivlin and Tator (35). After 30 seconds of compression duration the aneurysm clip was removed and a contusion field was observed on each spinal cord. Then the wound was closed in layers with $3 / 0$ atraumatic silk sutures and the animals were followed-up for the following five days. The level of the functional recovery was recorded at the first, third and fifth day postoperatively. All the animals were reanesthetised as described before and sacrificed five days after the procedure with the intracardiac injection of $2 \mathrm{cc} \mathrm{KCl}$ solution. Spinal cord specimens were harvested using the previous surgical incision and were fixed in $0.1 \mathrm{~mol}$ phosphate-buffered $2.5 \%$ glutaraldehyde solution.

\section{Functional Recovery Assessment}

Recovery of the neurological function was assessed with the inclined plane technique of Rivlin and Tator $(34,35)$ and a modified Tarlov's motor grading system (40). Investigators performed the assessment in a blinded fashion.

\section{Histological Evaluation}

Hematoxylin \& Eosin (HE) and TdT-mediated dUTP-biotin nick and labeling (TUNEL) staining were used for histological evaluation. Specimens were fixed in $0.1 \mathrm{~mol}$ phosphatebuffered $2.5 \%$ glutaraldehyde solution and embedded in paraffin. Sections were obtained from the center of the lesion. These $5 \mu \mathrm{m}$-thick, transversely-cut sections were stained with $\mathrm{HE}$. The samples were examined with a light microscope at a magnification level of $\times 20$.

The TUNEL method was used to evaluate apoptotic cell death (10). $5 \mu \mathrm{m}$-thick sections were prepared for TUNEL staining. The whole section was evaluated and all of the apoptotic cells were counted. A histopathologist who was not involved in the study counted the apoptotic cells with a light microscope under $\times 20$ magnification. The percentage of the apoptotic cells among all cells was recorded and classified as Grade 1 (0-25\%), Grade 2 (25-50\%), Grade 3 (50-75\%) and Grade 4 (75-100\%). In addition to the number and percentage of the apoptotic cells, the number of polymorphonuclear leukocytes (PNL) was also noted and the percentage among all inflammatory cells 
was calculated as an indicator of inflammation and necrosis $(9,12,13)$. Cavitation areas were also noted to assess necrosis $(9,12,13)$. Necrosis was assessed quantitatively among the study groups and again it was recorded as a percentage.

\section{Statistical Analysis}

Statistical comparisons between the study groups were made with the Kruskal-Wallis variance analysis and Mann-Whitney $\mathrm{U}$ test, except the parametric data from the motor evaluation with the inclined-plane technique. Parametric data were analyzed with ANOVA variance analysis and the Scheffe test for multiple comparisons. All results are based on two-sided tests for $p=0.05$.

\section{RESULTS}

\section{Functional Recovery}

Inclined plane test results of Group 3 and 5 (Q-VD-Oph and combined treatment groups) at the first, third and fifth postoperative day were better compared to Group 1, 2 and 4 (trauma, placebo and memantine treatment groups) and the difference was statistically significant $(p<0.001)$. There were no statistically significant differences between Group 3 and 5 .

Functional assessment by using "Tarlov motor grading scale" again showed statistically significantly better results in Group 3 and 5 compared to the other three groups. The "Tarlov motor grading scale" mean scores were 1 for each group on Day 1 and 3. The mean scores were 1 for individuals of Group 1, 2 and 4; and 2 for Group 3 and 5. No statistically significant differences were found between Group 3 and Group 5 ( $p>0.05$ ). Details of functional recovery according to the inclined plane test among the study groups were listed in Table I.

\section{Histological Findings}

The results for TUNEL staining and apoptotic cell counts revealed statistically significant differences in Q-VD-Oph and combined treatment groups (Group 3 and 5) compared to the other groups. The number and the percentage of the apoptotic cells were significantly reduced in Group 3 and 5 $(p<0.001)$ (Figures 1-5).

There was a significant difference in the means of PNL counts as well as percentages in the memantine and combined treatment groups (Groups 4 and 5) compared to the other groups $(p<0.001)$, but no difference was found in between them ( $p>0.05)$. The prevention of necrosis was also found to be more effective in the memantine and combined treatment groups compared to the other three study groups. The results for histological assessment are summarized in Table II and Table III.

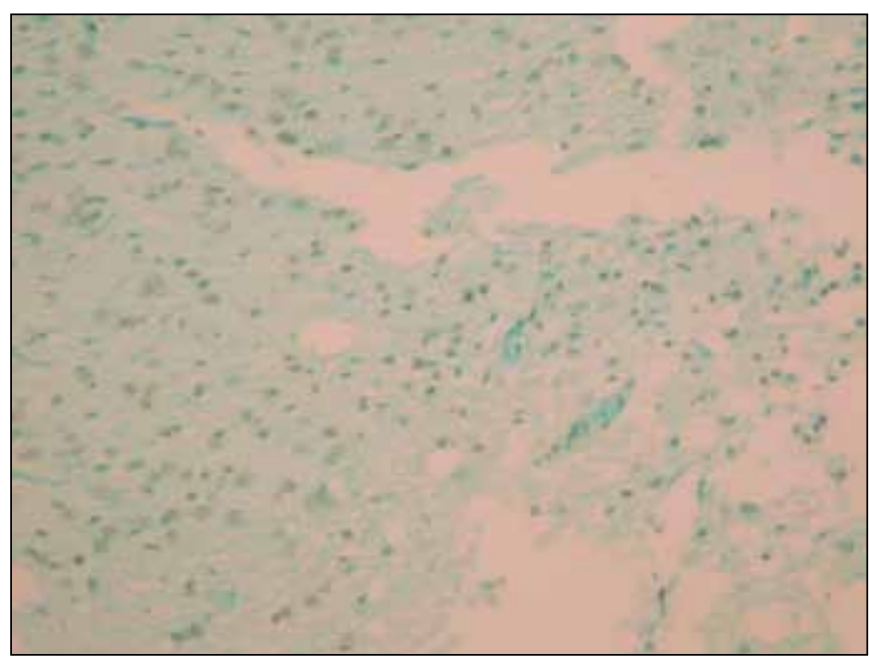

Figure 1: TUNEL staining of a subject from the trauma group shows increased number of apoptotic cells (x20).

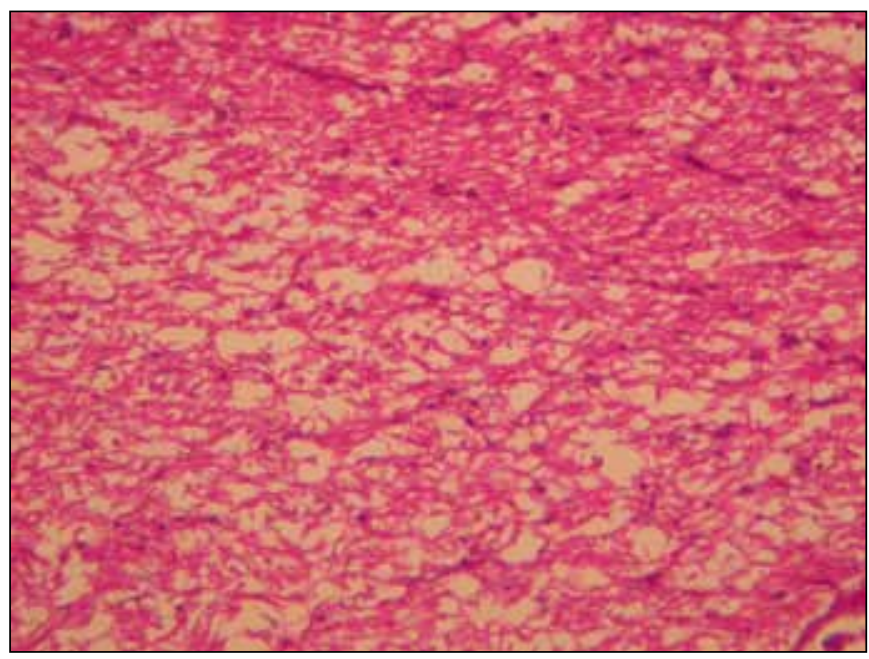

Figure 2: HE staining of the same specimen shows dense cavitation areas (x20).

Table I: Summary of Inclined Plane Results for the Five Groups of Rats

\begin{tabular}{lccc}
\hline Inclined Plane (degree) & Day 1 & Day 3 & Day 5 \\
\hline Group-1 & $27.78 \pm 0.97$ & $28.11 \pm 1.36$ & $28.44 \pm 1.01$ \\
\hline Group-2 & $27.67 \pm 0.71$ & $28.00 \pm 0.87$ & $27.78 \pm 0.67$ \\
\hline Group-3 & $31.89 \pm 0.78$ & $33.00 \pm 1.00$ & $34.00 \pm 0.87$ \\
\hline Group-4 & $27.89 \pm 0.78$ & $28.00 \pm 0.71$ & $27.89 \pm 0.60$ \\
\hline Group-5 & $32.56 \pm 0.53$ & $33.56 \pm 0.53$ & $34.56 \pm 0.53$ \\
\hline F & 91.509 & 84.899 & 185.379 \\
\hline
\end{tabular}




\section{DISCUSSION}

Secondary damage following traumatic $\mathrm{SCl}$ is mainly caused by two major mechanisms of cell loss: Apoptosis and necrosis. Excitatory neurotransmitters like glutamate and aspartate are

Table II: PNL and Lymphocyte Counts as Percentage

\begin{tabular}{lcc}
\hline & Lymphocyte \% & PNL\% \\
\hline Group-1 & 100 & 100 \\
\hline Group-2 & 88.9 & 88.9 \\
\hline Group-3 & 88.9 & 88.9 \\
\hline Group-4 & 11.1 & 11.1 \\
\hline Group-5 & 22.2 & 11.1 \\
\hline
\end{tabular}

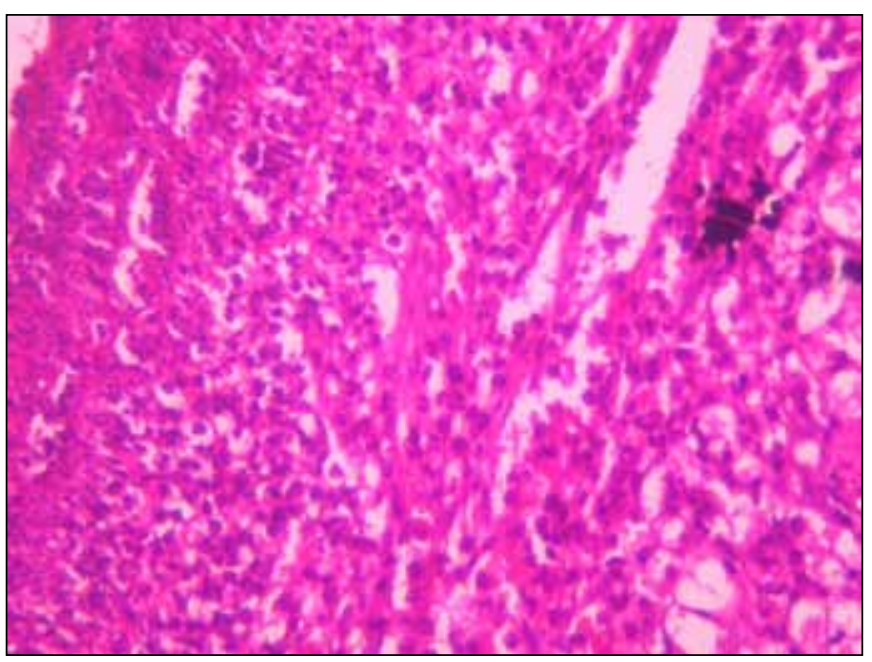

Figure 3: HE staining of a subject from memantine group. The decreased number of cavitation areas compared to trauma group draws attention $(x 20)$.

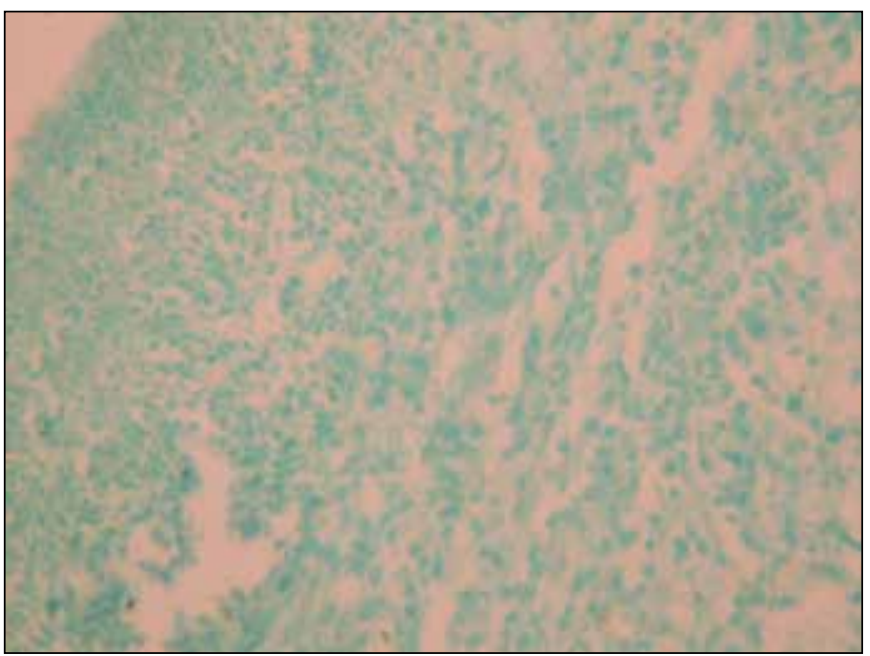

Figure 4: TUNEL staining of a subject from combined treatment group with decreased number of apoptotic cells and cavitation areas (x20). the primary neurotransmitters in the central nervous system. In case of a decrease in cellular energy levels due to conditions like ischemia, trauma or neurodegenerative processes, these excitatory neurotransmitters play a crucial role in neuronal degeneration and necrosis $(7,23)$. Under pathological circumstances the levels of these neurotransmitters may increase and lead to excitotoxicity (8). They bind to NMDA receptors and trigger calcium and sodium ion influx into the cells $(8,15)$. It has been shown in experimental $\mathrm{SCl}$ models that excitatory neurotransmitters may reach toxic levels in just 15 minutes following the trauma $(30,44)$. Therefore, NMDA receptor blockage has been thoroughly investigated and both competitive and non-competitive NMDA receptor antagonists have been used. Memantine is a clinically well-tolerated, noncompetitive NMDA antagonist, which is primarily used for the treatment of Parkinson's disease, dementia, multiple sclerosis and other neurological disorders $(11,31,32)$. Controversies exist regarding the neuroprotective effects of memantine in $\mathrm{SCl}$. Ehrlich et al. demonstrated the neuroprotective effects of memantine both clinically and electrophysiologically in an experimental spinal cord ischemia and reperfusion model in rabbits (8). However, in a study by von Euler et al., memantine was found to be ineffective in preventing secondary damage in SCl both histologically and clinically (42).

Apoptosis is a "programmed cell death" and it is an active process with the need of cellular protein synthesis and energy use $(4,18,24)$. Compared to necrosis, it is a more delayed process, with the autodigestion of the cells through enzymatic reactions and macrophage phagocytation and with the lack of inflammatory reactions $(5,18,20,21,25)$. Caspase-dependent signaling pathways play a crucial role in the induction of apoptosis. Initiator caspases like caspase-8 and caspase- 9 create the apoptotic stimulus and activate effector caspases like caspase-3,-6 and -7 (45). Several different caspase inhibitors were defined and used in experimental studies in order to block the apoptotic cascades on specific molecular stages $(3,16,28)$. Q-VD-OPh is a strong, new generation

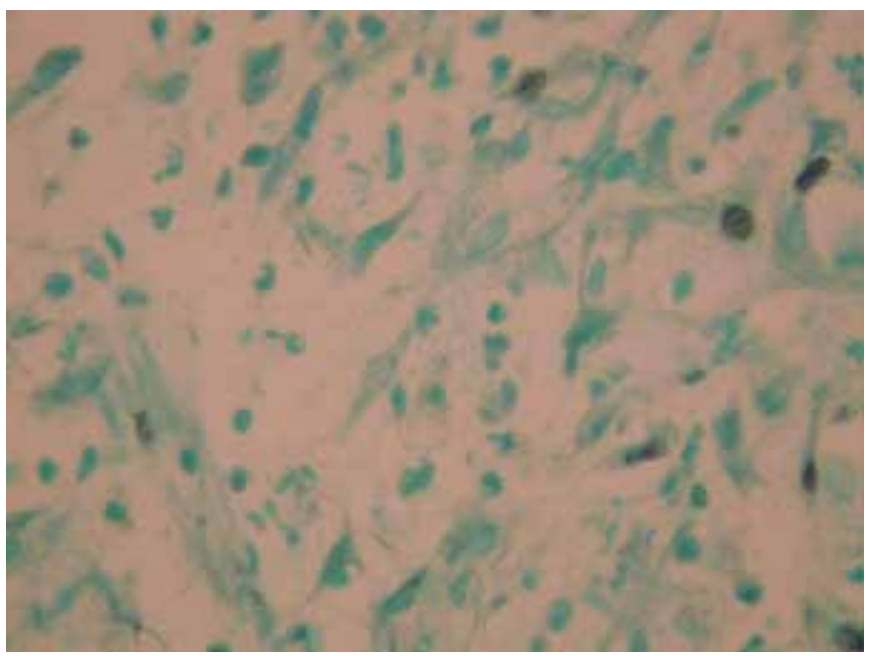

Figure 5: TUNEL staining of a subject form Q-VD-Oph group with a decrease in apoptotic cells, but still with presence of cavitation areas $(x 20)$. 
Table III: The Presence of Apoptosis and Necrosis as Percentage among the Five Experiment Groups

\begin{tabular}{lcccccc}
\hline & \multicolumn{2}{c}{ Apoptosis } & \multicolumn{2}{c}{ Necrosis } \\
\hline Study Groups & Grade 1 & Grade 2 & Grade 3 & Grade 4 & $-(\%)$ & $+(\%)$ \\
\hline Group-1 & 0 & 11.1 & 55.6 & 33.3 & 0 & 100 \\
\hline Group-2 & 0 & 0 & 66.7 & 33.3 & 0 & 100 \\
\hline Group-3 & 77.8 & 22.2 & 0 & 0 & 11.1 & 88.0 \\
\hline Group-4 & 0 & 11.1 & 66.7 & 22.2 & 77.8 & 22.2 \\
\hline Group-5 & 77.8 & 22.2 & 0 & 0 & 88.9 & 11.1 \\
\hline
\end{tabular}

pancaspase inhibitor, which irreversibly inhibits the three major pathways of the apoptosis (1). Other commonly used inhibitors, which consist of o-methylated peptides to provide cellular permeability, have one major weakness: toxicity (1). This highly specific and wide-spectrum caspase inhibitor showed no significant toxicity even in relatively high concentrations (1). In an experimental study by Renolleau et al., the effects of Q-VD-OPh on cerebral ischemic hypoxia has been investigated and compared to the control group, a $48 \%$ decrease in infarct volume and significant decrease in the number of apoptotic cells has been observed (33). Q-VDOPh was found to be effective in preventing apoptosis in cells infected with the coxsackie-B3 virus (25). White et al. demonstrated that Q-VD-OPh provided a delay in neuronal death following heat-induced stress in a cell culture of rat striatal neurons (43). Colak et al. showed the efficacy of $\mathrm{Q}-\mathrm{VD}-\mathrm{OPh}$ in preventing secondary injury following $\mathrm{SCl}$ (4). To our knowledge, this study is the only application of Q-VD$\mathrm{OPh}$ in experimental SCl. These and many other studies provide satisfactory results regarding the use of Q-VD-OPh for inhibition of apoptosis, without any toxic effects in a fairly extensive range of doses $(27,29,41)$. The increased permeability also may encourage investigators for its use in the central nervous system, both in clinical and experimental studies.

NMDA receptor inhibition alone seems like a reasonable option for the prevention of secondary damage in $\mathrm{SCl}$ with some promising results in experimental studies. However in cell cultures without glucose and oxygen support, it was shown that the inhibition of excitotoxicity with NMDA receptor antagonists leads to cell death thorough apoptosis $(22,24)$. Another study showed that the inhibition of one of the major pathways of cell death leads to the activation of the other pathway (45). So, theoretically inhibition of only one major pathway of cell death may not provide a sufficient effect in $\mathrm{SCl}$. Therefore we planned to use a combination of two drugs, which separately blocks two different pathways of cell death; namely apoptosis and necrosis. These two drugs are also known for their permeability across the blood-brain barrier $(17,26)$. To our knowledge the current study is only the second investigation based on this rationale (37).

In our study, there was a significant decrease in the number and percentage of apoptotic cells with the application of Q-VD$\mathrm{OPh}$, as expected. The least number of apoptotic cells was achieved in the Q-VD-OPh and combined treatment groups, which is in accordance with the current literature by means of the antiapoptotic effectiveness of Q-VD-OPh. Memantine provided a significant decrease in inflammatory cell and necrosis counts, again as expected. We found memantine to be effective in the prevention of secondary damage in $\mathrm{SCl}$ via inhibition of necrosis, at least histologically. However, the best clinical results were obtained again in the Q-VD-OPh and combined treatment groups. Both the Tarlov motor grading scale scores and inclined plane scores seemed slightly better for the combined treatment group and Q-VD-OPh group with no significant difference among them. Memantine alone did not provide any improvement in functional recovery.

Compared to other studies, only a limited functional recovery was achieved in our study. The best postoperative Tarlov motor grading scale score was no more than 2 among all of the study groups and the best postoperative inclined plane degree was 35. These results may be related with the different methods of $\mathrm{SCl}$ production. In the current literature, the weight-drop technique was more commonly used. However, the weight drop technique has been criticized for the difficulty to produce a uniform standardized trauma. We used the clip compression technique, which resulted in paraplegia and a Tarlov score of 1 for each of the rats. However, similar studies like the study of Colak et al., were related with better Tarlov scores even in the trauma group without treatment: a mean $1.4 \pm 0.28$ (4). Other studies also showed the same characteristics. This data indicates that in some experimental studies a paraparesis was achieved instead of paraplegia with the weight drop technique. Again the inclined plane results were better in most studies compared to ours (more than 40 degrees for the trauma group without treatment), probably due to the same reason. Independent from the technique, our results suggest that Q-VD-OPh provides significant improvement regarding the histological and functional results and memantine provides significantly better histological results. The combined use also results in good histological and clinical outcome.

\section{CONCLUSION}

Individual and combined use of memantine and Q-VD-OPh provides statistically better histological and clinical results. Memantine was found to be effective in prevention of necrosis following SCI. Q-VD-OPh was found to be effective in prevention of apoptosis following SCl. The clinical results 
were significantly better for the Q-VD-OPh and combined treatment groups. The combined use of these drugs provides effective prevention of secondary damage after $\mathrm{SCl}$ at least histologically. The combined inhibition of the two major pathways, necrosis and apoptosis need to be further assessed with in-vivo or in-vitro studies in order to create more effective treatment modalities.

\section{- REFERENCES}

1. Caserta TM, Smith AN, Gultice AD, Reedy MA, Brown TL: Q-VD-OPh, a broad spectrum caspase inhibitor with potent antiapoptotic properties. Apoptosis 8: 345-352, 2003

2. Choi DW, Maulucci-Gedde M, Kriegstein AR: Glutamate neurotoxicity in cortical cell culture. J Neurosci 7:357-368, 1987

3. Colak A, Karaoglan A, Barut S, Kokturk S, Akylldz Al, Tasyurekli M: Neuroprotection and functional recovery after application of the caspase 9 inhibitor z-LDH-fmk in a rat model of traumatic spinal cord injury. J Neurosurg Spine 2(3): 327-334, 2005

4. Colak A, Antar V, Karaoglan A, Akdemir O, Sahan E, Celik O, Sagmanligil A: Q-VD-OPh, a pancaspase inhibitor reduces trauma induced apoptosis and improves the recovery of hindlimb function in rats after spinal cord injury. Neurocirugia 20: 533-540, 2009

5. Cummings MC, Winterford CM, Walker NI: Apoptosis. Am J Surg Pathol 21(1): 88-101, 1997

6. Dickens BF, Weglicki WB, LiYS, Mak IT: Magnesium deficiency in vitro enhances free radical induced intracellular oxidation and cytotoxicity in endothelial cells. FEBS Lett 311:187-191, 1992

7. Dumont RJ, Verma S, Okonkwo DO, Hurlbert RJ, Boulos PT, Ellegala DB, Dumont AS: Acute spinal cord injury, part II: contemporary pharmacotherapy. Clin Neuropharmacol 24: 265-279, 2001

8. Ehrlich M, Knolle E, Ciovica R, Bock P, Turkof E, Grabenwöger M, Cartes-Zumelzu F, Kocher A, Pockberger H, Fang WC, Wolner E, Havel M: Memantine for prevention of spinal cord injury in a rabbit model. J Thorac Cardiovasc Surg 117(2): 285-291, 1999

9. Fujiki M, Furukawa $Y$, Kobayashi $H$, Abe $T$, Ishii $K$, Uchida S, Kamida T: Geranylgeranylacetone limits secondary injury, neuronal death, and progressive necrosis and cavitation after spinal cord injury. Brain Res 1053: 175-184, 2005

10. Gavrieli Y, Sherman Y, Ben-Sasson SA: Identification of programmed cell death in situ via specific labeling of nuclear DNA fragmentation. J Cell Bio 119: 493-501, 1992

11. Gorgulu A, Kins T, Cobanoglu S, Unal F, Izgi NI, Yanik B, Kucuk $M$ : Reduction of edema and infarction by memantine and MK801 after focal cerebral ischemia and reperfusion in rat. Acta Neurochir 142: 1287-1292, 2000

12. Guth L, Barrett CP, Donati EJ, Anderson FD, Smith MV, Lifson $M$ : Essentiality of a specific cellular terrain for growth of axons into a spinal cord lesion, Exp. Neurol 88:1-12, 1985

13. Guth L, Zhang Z, Roberts E: Key role for pregnenolone in combination therapy that promotes recovery after spinal cord injury Proc Natl Acad Sci USA 91:12308 -12312, 1994
14. Kaptanoglu E, Beskonakli E, Solaroglu I, Kilinc A, Taksin Y: Magnesium sulphate treatment in experimental spinal cord injury: Emphasis on vascular changes and early clinical results. Neurosurg Rev 26: 283-287, 2003

15. Kaptanoglu E, Beskonakli E, Okutan O, Surucu S, Taskin Y: Effect of magnesium sulphate in experimental spinal cord injury: Evaluation with ultrastructural findings and early clinical results. J Clin Neurosci 10(3):329-334, 2003

16. Kaptanoglu E, Caner H, Solaroglu I, Kilinc K: Mexiletine treatment-induced inhibition of caspase 3 activation and improvement of behavioral recovery after spinal cord injury. $J$ Neurosurg Spine 3:53-56, 2005

17. Karatas H, Aktas Y, Gursoy-Ozdemir Y, Bodur E, Yemisci M, Caban S, Vural A, Pinarbasli O, Capan Y, Fernandez-Megia E, Novoa-Carballal R, Riguera R, Andrieux K, Couvreur P, Dalkara $\mathrm{T}$ : A nanomedicine transports a peptide caspase- 3 inhibitor across the blood-brain barrier and provides neuroprotection. J Neurosci 29(44):13761-13769, 2009

18. Kato H, Kanellopoulos GK, Matsuo S, Wu YJ, Jacquin MF, Hsu CY, Kouchoukos NT, Choi DW: Neuronal apoptosis and necrosis following spinal cord ischemia in the rat. Exp Neurol 148: 464-474, 1997

19. Kawabata H, Setoguchi T, Kazunori Y, Souda M, Yoshida H, Kawahara K, Maruyama I, Komiya S: High motility group box 1 is upregulated after spinal cord injury and is associated with neuronal cell apoptosis. Spine 35(11):1109-1115, 2010

20. Kwon BK, Tetzlaff W, Grauer JN, Beiner J, Vaccaro AR: Pathophysiology and pharmacologic treatment of acute spinal cord injury. Spine J 4(4):451-464, 2004

21. Li M, Ona VO, Chen M, Tenneti L, Zhang X, Stieg PE, Lipton SA, Friedlander RM: Functional role and therapeutic implications of neuronal caspase- 1 and -3 in a mouse model of traumatic spinal cord injury. Neuroscience 99:333-342, 2000

22. Liu XZ, Xu XM, Hu R, Du C, Zhang SX, McDonald JW, Dong HX, Wu YJ, Fan GS, Jacquin MF, Hsu CY, Choi DW: Neural and glial apoptosis after traumatic spinal cord injury. J Neurosci 15: 5395-5406, 1997

23. Lou J, Lenke LG, Ludwig FJ, O’Brien MF: Apoptosis as a mechanism of neuronal cell death following acute experimental spinal cord injury. Spinal Cord 36:683-690, 1998

24. Lu J, Ashwell K, Ken WS, Waite P: Advances in spinal cord injury: Role of apoptosis. Spine 25:1859-1866, 2000

25. Martin U, Jarasch N, Nestler M, Rassmann A, Munder T, Seitz S, Zell R, Wutzler P, Henke A: Antiviral effects of pancaspase inhibitors on the replication of coxsackievirus B3. Apoptosis 12: 523-533, 2006

26. Mehda C, Short JL, Nicolazzo JA: Memantine transport across the mouse blood-brain barrier is mediated by a cationic influx $\mathrm{H}+$ antiporter. Mol Pharm 10(12):4491-4498, 2013

27. Melnikov VY, Faubel S, Siegmund B, Lucia MS, Ljubanovic D, Edelstein CL: Neutrophil-independent mechanisms of caspase 1 and IL-18 mediated ischemic acute tubular necrosis in mice. J Clin Invest 110:1083-1091, 2002

28. Mouw G, Zechel JL, Zhou Y, Lust WD, Selman WR, Ratcheson RA: Caspase-9 inhibition after focal cerebral ischemia improves outcome following reversible focal ischemia. Metab Brain Dis 17:143-151, 2002 
Aydoseli A. et al: Memantine and Q-VD-OPh in Spinal Cord Injury

29. Nonner D, Panickar K, Barrett EF, Barrett JN: Bone morphogenetic proteins and neurotrophins provide complementary projection of septal cholinergic function during phosphatase inhibitor-induced stress. J Neurochem 91: 77-87, 2004

30. Panter SS, Yum SW, Faden AJ: Alteration in extracellular amino acids after traumatic spinal cord injury. Ann Neurol 27: 96-99, 1990

31. Parsons CG, Danyz W, Quack G: Memantine is a clinically well tolerated N-methyl-D-aspartate (NMDA) receptor antagonist: A review of preclinical data. Neuropharmacology 38: 735-767, 1999

32. Rehncrona S, Mela L, Siesco BK: Recovery of brain mitochondrial function in the rat after complete and incomplete cerebral ischemia. Stroke 10:437-446, 1979

33. Renolleau S, Fau S, Goyenvalle C, Joly LM, Chauvier D, Jacotot E, Mariani J, Charriaut-Marlangue C: Specific caspase inhibitor Q-VD-OPh prevents neonatal stroke in $\mathrm{P} 7$ rat: A role of gender. J Neurochem 100(4):1062-1071, 2007

34. Rivlin AS, Tator $\mathrm{CH}$ : Objective clinical assessment of motor function after experimental spinal cord injury in the rat. $J$ Neurosurg 47:577-581, 1977

35. Rivlin AS, Tator $\mathrm{CH}$ : Effect of duration of acute spinal cord compression in a new acute cord injury model in rat. Surg Neurol 9:39-43, 1978

36. Rokkas CK, Helfrich LR, Lobner DC, Choi DW, Kouchukos NT: Dextrorphan inhibits the release of excitatory amino acids during spinal cord ischemia. Ann Thorac Surg 58:312-320, 1994

37. Sencer A, Aydoseli A, Aras Y, Akcakaya MO, Gomleksiz C, Can $\mathrm{H}$, Canbolat $\mathrm{A}$ : Effects of combined and individual use of $\mathrm{N}$-methyl-D-aspartate receptor antagonist magnesium sulphate and caspase-9 inhibitor z-LEDH-fmk in experimental spinal cord injury. Ulus Travma Acil Cerrahi Derg 19(4):313319,2013
38. Sirbulescu RF, Zupane GKH: Inhibition of caspase-3-mediated apoptosis improves spinal cord repair in a regenerationcompetent vertebrate system. Neuroscience 171:599-612, 2010

39. Sugawara T, Lewen A, Gasche Y, Yu F, Chan PH: Overexpression of SODI protects vulnerable motor neurons after spinal cord injury by attenuating mitochondrial cytochrome $c$ release. FASEB J 16: 1997-1999, 2002

40. Tarlov IM: Spinal cord compression: Mechanism of paralysis and treatment. Springfield, Illinois: Charles C Thomas, 1957

41. Vera Y, Rodriguez S, Castanares M, Lue Y, Atienza V, Wang C, Swerdloff RS, Sinha Hikim AP: Functional role of caspases in heat-induced testicular germ cell apoptosis. Biol Reprod 72 : 516-522, 2005

42. von Euler M, Li-Li M, Whittemore S, Seiger A, Sundstrom E: No protective effect of the NMDA antagonist memantine in experimental spinal cord injuries. J Neurotrauma 14:53-61, 1997

43. White MG, Emery M, Nonner D, Banner JN: Caspase activation contributes to delayed death of heat-stressed striatal neurons. J Neurochem 87: 958-968, 2003

44. Xu GY, Hughes MG, Ye Z, Hulsebosch CE, McAdoo DJ: Concentrations of glutamate released following spinal cord injury kill oligodendrocytes in the spinal cord. Exp Neurol 187(2): 329-336, 2004

45. Yakovlev AG, Faden Al: Mechanisms of neural cell death: Implications for development of neuroprotective strategies. NeuroRx 1(1):5-16, 2004 